\title{
Neonatal Hemochromatosis
}

National Cancer Institute

\section{Source}

National Cancer Institute. Neonatal Hemochromatosis. NCI Thesaurus. Code C129980.

An idiopathic form of neonatal hemochromatosis, characterized by liver failure and iron accumulation in the tissues. 